\title{
The effect of Gypsophila saponins in the diet on mineral status and plasma cholesterol concentration in the rat
}

\author{
By SUSAN SOUTHON, I. T. JOHNSON, JENNIFER M. GEE \\ AND K. R. PRICE \\ AFRC Institute of Food Research, Norwich Laboratory, Colney Lane, Norwich NR4 7UA
}

(Received 17 July 1987 - Accepted 28 August 1987)

\begin{abstract}
1. Immature, male Wistar rats were allocated to one of six groups and caged individually. The first group was given a semi-synthetic diet containing $38 \mathrm{mg}$ iron and $55 \mathrm{mg} \mathrm{zinc} / \mathrm{kg}$ (basal group). The second and third groups were given a diet containing $10 \mathrm{mg} \mathrm{Zn}$ and $12 \mathrm{mg} \mathrm{Fe} / \mathrm{kg}$ respectively (low- $\mathrm{Zn}$ and low-Fe groups). Groups four, five and six were given similar diets containing $20 \mathrm{~g}$ Gypsophila saponins $/ \mathrm{kg}$. After $21 \mathrm{~d}$ the $\mathrm{Fe}$ and $\mathrm{Zn}$ status of the rats was estimated and plasma cholesterol concentration determined.

2. Measurements of whole blood haemoglobin concentration, packed cell volume and liver Fe stores indicated that rats in the basal + saponin and low-Fe + saponin groups had a significantly reduced Fe status when compared with their controls. Rats in the low- $\mathrm{Zn}+$ saponin group also showed a trend toward reduced Fe stores.

3. Zn status, as judged by femur $\mathrm{Zn}$ concentration, was not adversely affected by the inclusion of Gypsophila saponins in the diet.

4. Consumption of the saponins resulted in a significant reduction in blood cholesterol concentration, with rats in both the low-Fe groups having significantly lower concentrations than their basal and low-Zn counterparts.

5. In view of suggestions that the consumption of saponins should be encouraged because of their ability to lower blood cholesterol, possible effects on Fe metabolism should be investigated further, particularly with respect to the levels and sources of saponin in the human diet.
\end{abstract}

Saponins are glycosides which occur widely in a range of plants and are present in many foods consumed by animals and man (Cheeke, 1971). In view of the emphasis being placed on increasing the consumption of plant foods, the intake of saponins is also expected to increase. It has been suggested that increased consumption of saponins might be beneficial to some sections of the population because of the ability of many saponins to lower serum cholesterol markedly; elevated plasma cholesterol levels being a significant risk factor in the aetiology of cardiovascular disease (Malinow et al. 1981; Oakenfull, 1981).

There is, however, extensive evidence that saponins can also have deleterious effects, in that the inclusion of some saponins into feeds leads to reduced growth in poultry and simple-stomached mammals (Petersen, 1950; Cheeke et al. 1978). The mechanism by which growth is retarded is uncertain but it has been suggested that the primary effect is due to reduced palatability of the food (Cheeke et al. 1983), and indeed the consumption of feeds containing saponin is often associated with reduced food intake (Gaunt et al. 1974).

An alternative explanation is that the presence of saponins at high concentrations may limit the availability, for absorption or metabolism, of essential micro-nutrients. It has been reported, for example, that certain saponins form insoluble complexes with iron and zinc in vitro, and so may reduce the proportion of dietary mineral which is available for absorption in vivo (West et al. 1978). Fe and $\mathrm{Zn}$ deficiencies, like many other mineral deficiencies, can result in poor growth and development and in disorders of appetite. The present study was therefore undertaken to determine whether there is any indication that dietary saponins reduce mineral utilization in the rat model. The source of saponin for the study was a Gypsophila root extract which consists of a mixture of acidic triterpenoid saponins similar in structure to those found in a variety of foods consumed by humans (Price et al. $1987 a$ ).

In view of evidence that some human diets are of low mineral concentration and poor 
mineral availability (Southon et al. 1988), the investigation included diets which were low in Fe or $\mathrm{Zn}$, in addition to a normal mineral-replete diet. Effects which may not be apparent in animals maintained on optimal mineral levels, may become important when the diet is marginal in this respect.

\section{MATERIALS AND METHODS}

Animals and diets

Sixty immature, male Wistar rats (approximately $100 \mathrm{~g}$ ) were randomly divided into six groups of ten and caged individually. The first group was given a semi-synthetic diet containing $38 \mathrm{mg} \mathrm{Fe}$ and $55 \mathrm{mg} \mathrm{Zn/kg}$; this was designated the basal group. For the second and third groups the mineral mix was adjusted to give final dietary concentrations of 10 $\mathrm{mg} \mathrm{Zn}$ and $12 \mathrm{mg}$ Fe respectively, while maintaining basal levels of all other minerals; these groups were designated the low-Zn and low-Fe groups respectively. For groups four, five and six similar diets were prepared containing $20 \mathrm{~g}$ Gypsophila saponins $/ \mathrm{kg}$, isolated from the roots of Gypsophila sp. (Sigma Chemical Co., Poole, Dorset); these groups were designated the basal+saponin, low- $\mathrm{Zn}+$ saponin, and low-Fe + saponin groups respectively. The composition of the diet was similar to that previously described (Southon et al. 1985) with the addition of $2.5 \mathrm{~g}$ methionine $/ \mathrm{kg}$ diet. All rats received distilled water $a d$ lib. Preliminary studies showed that rats found the diets containing saponin less palatable than the normal control diet, particularly over the first 4-5 d of feeding, after which intake rose to approximately $80 \%$ of the control value. To determine the effect of the saponin per se on mineral status and blood cholesterol concentration it was necessary to control food intake so that all animals consumed the same amount. Rats received $5 \mathrm{~g}$ food/d for the first $2 \mathrm{~d}, 10 \mathrm{~g} / \mathrm{d}$ for the next $2 \mathrm{~d}$, followed by $12 \mathrm{~g} / \mathrm{d}$ rising to $20 \mathrm{~g} / \mathrm{d}$ towards the end of the experiment. Allowance was made each day for any spillage of food. All animals were killed in random order on day 21 and $\mathrm{Fe}$ and $\mathrm{Zn}$ status estimated.

\section{Experimental}

Rats were deeply anaesthetized by intraperitoneal injection of sodium pentabarbital $(160 \mathrm{mg} / \mathrm{ml} ; 1 \mathrm{ml} / \mathrm{kg}$ body-weight) and killed by cervical dislocation. The abdomen was opened and a sample of blood $(2.5 \mathrm{ml})$ obtained from the vena cava and transferred to a heparinized vial. The liver was excised, rinsed in ice-cold saline $(9 \mathrm{~g}$ sodium chloride/ 1 distilled water), blotted dry and weighed.

The whole liver and femur were dried at $80^{\circ}$ for $24 \mathrm{~h}$, reweighed and ground to a fine powder. Weighed samples were ashed at $470^{\circ}$ for $48 \mathrm{~h}$, the ash dissolved in a minimum volume of concentrated hydrochloric acid (11.5 $\mathrm{M}-\mathrm{HCl}$; Analar; BDH) and, after further dilution with distilled water, analysed for $\mathrm{Zn}$ and $\mathrm{Fe}$ by atomic absorption spectroscopy.

Haemoglobin $(\mathrm{Hb})$ concentration was measured in samples $(40 \mu \mathrm{l})$ of whole blood by the cyanmethaemoglobin method (Cannon, 1958). Approximately $50 \mu 1$ blood was taken up into a heparinized heamatocrit tube for the determination of packed cell volume (PCV), which was expressed as a proportion of total blood volume.

Total cholesterol concentration was determined in plasma using the Boehringer CHODPAP method (Boehringer Corporation Ltd, Lewes, Sussex). Samples (20 $\mu 1$ undiluted plasma or standard cholesterol solution, range $0-10.3 \mathrm{mmol} / 1$ in propan-2-ol) were incubated at $20-25^{\circ}$ with Test System Reagent for $10 \mathrm{~min}$, and the absorbance at $500 \mathrm{~nm}$ measured against a reagent blank within $1 \mathrm{~h}$. Results were expressed as $\mu$ mol cholesterol/ ml plasma. 


\section{Isolation and partial characterization of Gypsophila saponin}

Crude saponin from Sigma Chemical Co. was purified by means of reversed-phase flash chromatography (Price et al. $1987 \mathrm{~b}$ ). Crude saponin $(1 \mathrm{~g})$ was dissolved in water $(25 \mathrm{ml})$ and eluted through a column of octasilane bonded to silica gel (40 g) (J. T. Baker Chemical Co. Phillipsburg, N.J.) successively with water $(375 \mathrm{ml})$ and redistilled Analar methanol $(375 \mathrm{ml})$. The methanol fraction was collected and evaporated under reduced pressure which gave a saponin mixture representing $604 \mathrm{~g} / \mathrm{kg}$ starting material. The aqueous fraction was freeze-dried. Portions of each were dissolved in aqueous methanol and subjected to reversed-phase high-performance thin layer chromatography (RP-HPTLC) using octadecyl silane-bonded silica $(100 \times 100 \mathrm{~mm}$; BDH-Merck, Poole) and developed for $55 \mathrm{~mm}$ with a solvent mixture comprising methanol-water $(3: 2, \mathrm{v} / \mathrm{v})$. Seven spots with $R_{\mathrm{f}}$ values ranging from 0.24 to 0.54 were observed for the methanol 'saponin' fraction, while the aqueous 'non-saponin' fraction contained only one spot running close to the solvent front.

Further analysis of these two fractions were carried out using the products of their acid hydrolysis. A portion of each fraction $(25 \mathrm{ml})$ was hydrolysed using $50 \mathrm{ml} \mathrm{HCl} / 1$ methanol $(4 \mathrm{ml})$ for $3 \mathrm{~h}$ under reflux conditions, neutralized with alkali $(0.880 \mathrm{ammonia})$ and extracted with ethyl acetate $(3 \times 5 \mathrm{ml})$. The combined ethyl acetate layers were dried over sodium sulphate, evaporated to dryness and converted to their trimethylsilyl derivatives using bis-trimethylsilyltrifluoracetamide $(200 \mu \mathrm{l})$ in pyridine $(200 \mu \mathrm{l})$ at $50^{\circ}$ for $30 \mathrm{~min}$. Each sample was analysed by gas-liquid chromatography using a Perkin-Elmer Sigma 3B chromatograph fitted with a $1 \mathrm{~m} \times 2 \mathrm{~mm}$ i.d. column containing $3 \% \mathrm{OVl}$ on diatomite $\mathrm{CO}$ (100-200 mesh) with a flow-rate of $35 \mathrm{ml} / \mathrm{min}$ and oven temperature of $280^{\circ}$. No derivatives of an acid-released aglycone were detected in the aqueous fraction while a major peak in the methanol fraction was identified from its retention time, and by subsequent coupled gas-liquid chromatography-mass spectrometry, as gypsogenic acid, the aglycone known to be present in the Gypsophila saponins (Luchanskaya et al. 1971). Due to the lack of knowledge on the composition of the individual Gypsophila saponins and hence the carbohydrate:gypsogenic acid ratios, no absolute value for saponin purity can be given from the information quoted. However, all the evidence suggests that the methanol fraction contains only saponin, while the aqueous phase contains compounds which do not exhibit chromatographic or chemical properties typical of saponins.

Assuming therefore that the commercially supplied saponin was $60.4 \%$ pure, the concentration of Gypsophila saponin in the diets consumed by the 'saponin' groups of rats was $12 \mathrm{~g} / \mathrm{kg}$.

\section{Statistical analysis}

The significance of difference between means was estimated by Student's $t$ test for unpaired comparisons.

\section{RESULTS}

In a preliminary feeding trial it was found that the daily food intake of rats given diets containing $20 \mathrm{~g}$ crude Gypsophila saponins/ $\mathrm{kg}$ diet was initially only $60 \%$ of the value for control animals, rising to $80-90 \%$ after approximately $5 \mathrm{~d}$. In order to assess the effect of the saponin per se on mineral status and blood cholesterol levels, it was necessary to limit the food intake of the control rats. All rats were given the same amount of food each day, which was estimated from preliminary food intake values and the total food intake for each animal over the $21 \mathrm{~d}$ experimental period was $303 \mathrm{~g}$.

The body-weight gain of the basal + saponin and low-Fe + saponin rats over this period 


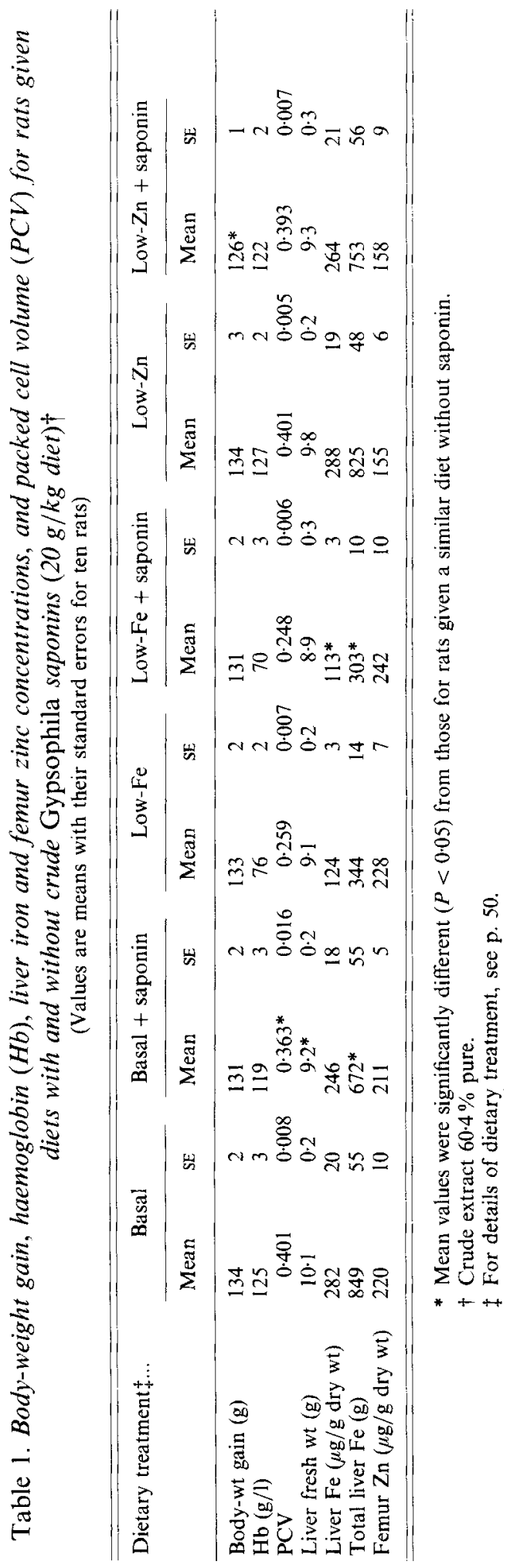


Table 2. Total cholesterol concentration in plasma from rats given diets with and without Gypsophila saponin

(Values are means with their standard errors for ten rats)

\begin{tabular}{lll}
\hline & \multicolumn{2}{c}{ Cholesterol $(\mu \mathrm{mol} / \mathrm{ml}$ plasma $)$} \\
\cline { 2 - 3 } Dietary treatment & Mean & SE \\
\hline Basal & $2 \cdot 76$ & $0 \cdot 11$ \\
Basal + saponin & $2 \cdot 28^{*}$ & $0 \cdot 06$ \\
Low-Fe & $2 \cdot 44 \dagger$ & $0 \cdot 08$ \\
Low-Fe + saponin & $1 \cdot 89^{* \dagger}$ & $0 \cdot 04$ \\
Low-Zn & $2 \cdot 80$ & $0 \cdot 10$ \\
Low-Zn+saponin & $2 \cdot 49^{*}$ & $0 \cdot 09$ \\
\hline
\end{tabular}

* Mean values were significantly different $(P<0.05)$ from those for rats given a similar diet without saponin.

$\dagger$ Mean values significantly different $(P<0.05$ ) from basal and low-Zn counterparts.

$\ddagger$ For details of dietary treatment, see p. 50 .

was not significantly different from that of rats given a similar saponin-free diet, but the weight gain of the low- $\mathrm{Zn}+$ saponin animals was lower than that of their controls, despite the pair-feeding regimen (Table 1 ).

Measurements of whole-blood $\mathrm{Hb}$ concentration, PCV and liver Fe stores indicated that rats in the basal + saponin and low- $\mathrm{Fe}+$ saponin groups had a reduced $\mathrm{Fe}$ status when compared with their controls. The basal + saponin group, which received an adequate level of dietary Fe, had significant reductions in PCV and liver Fe stores, compared with rats given a similar diet without saponin. The decrease in total liver $\mathrm{Fe}$ was partly related to a reduction in liver fresh weight, but mean liver Fe concentration was also slightly lower (Table 1). Rats consuming the low-Fe diet with added saponin had significant reductions in both liver Fe concentration and total liver Fe, compared with their controls (Table 1). There was no significant change in PCV or liver Fe stores in the low- $\mathrm{Zn}+$ saponin animals, but mean values for liver Fe concentration and total liver Fe were lower than those for the low-Zn group (Table 1).

$\mathrm{Zn}$ status, as judged by femur $\mathrm{Zn}$ concentration, was not adversely affected by the inclusion of $12 \mathrm{~g}$ Gypsophila saponins $/ \mathrm{kg}$ diet. It was noted, however, that the $\mathrm{Zn}$ concentration in femurs taken from the low-Fe+ saponin rats was significantly higher $(P<0.05)$ than that for rats given a mineral-replete diet containing the saponin (Table 1).

Inclusion of Gypsophila saponins in the diet resulted in a significant reduction in the blood cholesterol level in each of the three dietary groups. This hypocholesterolaemic effect appeared to be greater when the saponin was incorporated into the low-Fe diet; reductions in cholesterol concentration being 11,17 and $23 \%$ in the low- $\mathrm{Zn}+$ saponin, basal + saponin and low-Fe + saponin groups respectively. Cholesterol concentration was also influenced by dietary $\mathrm{Fe}$ concentration, since rats in the low-Fe and low-Fe + saponin groups had significantly lower concentrations than their basal and low-Zn counterparts (Table 2).

\section{DISCUSSION}

Recently, it has been strongly suggested that consumption of foods rich in saponin, or supplements of the purified component, could be beneficial in terms of reducing hypercholesterolaemia, aortic atherosclerosis and deposition of tissue cholesterol in man 
(Malinow et al. 1980). However, there is some indication in the literature that certain saponins may adversely influence mineral absorption. West et al. (1978) clearly demonstrated that $\mathrm{Fe}$ and $\mathrm{Zn}$ are complexed and precipitated by lucerne (Medicago sativa) root saponin in vitro, whilst animal studies showed that feeding lucerne plant saponins increased faecal Fe and magnesium loss in rats (Cheeke, 1980), and decreased plasma calcium and $\mathrm{Zn}$ in pigs (Pond \& Yen, 1984). The present study was undertaken, therefore, to determine whether there was any indication of impaired mineral status in rats following prolonged consumption of diets containing a level of saponin generally considered to have little or no toxic effect (Gaunt et al. 1974; Reshef et al. 1976). Since Fe and Zn appeared to be strongly complexed by certain saponins (West et al. 1978), the investigation concentrated on these two essential minerals.

Chemically pure saponins are difficult to obtain in amounts necessary to conduct longterm feeding experiments, consequently the material used in the present study was a commercially available extract of Gypsophila root which consists of a mixture of acidic triterpenoid saponins and is of variable purity. The material used in the present study was determined to contain $604 \mathrm{~g}$ saponins $/ \mathrm{kg}$ crude extract.

The body-weight gain of animals in the study was generally similar, when food intake was equalized between the 'saponin' and 'non-saponin' groups. There was, however, a small but significant growth depression in rats given saponin incorporated into a low- $\mathrm{Zn}$ diet. A reduction in the availability of $\mathrm{Zn}$ to the body, coupled with the lower $\mathrm{Zn}$ concentration of the diet given to the low- $\mathrm{Zn}$ groups of animals, might be expected to result in some growth retardation in young rats. However, femur $\mathrm{Zn}$ concentration indicated that the Zn status of each of the three 'saponin' groups of rats was as good as their respective control group, and possibly even better in the case of the low-Fe + saponin rats. At present it is difficult to interpret the difference in growth between the low- $\mathrm{Zn}$ and low$\mathrm{Zn}+$ saponin animals, but it seems unlikely to be associated with a reduction in $\mathrm{Zn}$ absorption.

Rats consuming saponin added to a low-Fe and a mineral-replete diet showed evidence of a significant reduction in Fe status compared with their control group and, although values for the low- $\mathrm{Zn}$ and low- $\mathrm{Zn}+$ saponin groups were not significantly different, both the mean liver Fe concentration and total liver Fe were lower in the animals consuming saponin. The haemolytic properties of saponins are well known, but it is generally agreed that they are not readily absorbed, and that the normal environment of the erythrocytes counteracts their haemolytic activity (Bondi et al. 1973; Cheeke, 1980). It is more likely, therefore, that the lower $\mathrm{Fe}$ status observed in rats consuming saponins resulted from reduced $\mathrm{Fe}$ absorption, rather than a metabolic disturbance caused by saponins entering the bloodstream. One possible explanation for differences in absorption as suggested by the work of West et al. (1978) is that acidic triterpenoid saponins form complexes with dietary Fe thus rendering it unavailable for absorption. Alternatively, it is possible that the longterm consumption of these saponins produces changes in mucosal function such that $\mathrm{Fe}$ transport is impaired. It is well-known that saponins have a high affinity for cholesterol and so can become incorporated into the structure of the cell membrane to form stable porelike structures (Seeman, 1974). Gypsophila saponins readily render permeable intestinal absorptive cells in vitro, and destroy their capacity for the accumulation of sugars (Johnson et al. 1986). It is possible therefore that dietary saponins may exert a similar effect in the intact animal, and hence reduce the efficiency of nutrient absorption, in which case it would be expected that $\mathrm{Zn}$ as well as $\mathrm{Fe}$ absorption would be affected. Since there was no indication of reduced $\mathrm{Zn}$ status in the 'saponin' groups of rats it appears that the first of these two possibilities is the more likely.

The present study also demonstrates a hypocholesterolaemic effect of Gypsophila 
saponins, which was apparently influenced by the Fe content of the diet, or possibly the $\mathrm{Fe}$ status of the animal itself. The hypocholesterolaemic property of certain saponins is well documented (Cheeke, 1971) but the significant reduction in plasma cholesterol observed in rats given the 'saponin-free' low-Fe diet compared with the other control groups, and the increased potency of the saponin when incorporated into this diet, is puzzling and suggests an interesting saponin-mineral interaction which has not previously been documented.

In the context of the present study the effect of saponin on mineral status was limited to Fe. In view of suggestions that the consumption of saponins by man should be positively encouraged, and the fact that frank and occult $\mathrm{Fe}$ deficiency is a relatively common problem in the human population (Monsen et al. 1978), it is important that the nature of this effect is investigated further, particularly in relation to the levels and sources of saponin in the human diet. Obtaining pure samples of saponin from any source is difficult (Price et al. 1987 a), consequently crude extracts, or foods rich in saponin, are routinely used to prepare experimental diets. The possibility that the 'non-saponin' fraction of these materials is in some way responsible for the physiological effects reported in the present and other studies has been considered, but thought unlikely. Nevertheless, future work will take account of this possibility.

\section{REFERENCES}

Bondi, A., Birk, Y. \& Gestetner, B. (1973). In Chemistry and Biochemistry of Herbage, pp. 511-528 [I. G. W. Butler and R. W. Baily, editors]. London: Academic Press.

Cannon, R. K. (1958). Clinical Chemistry 4, 246-251.

Cheeke, P. R. (1971). Canadian Journal of Animal Science 51, 621-623.

Cheeke, P. R. (1980). In Leaf Protein Concentrates, pp. 396-414 [L. Telek and H. D. Graham, editors]. Westport, Connecticut: Avi Publishing Co. Inc.

Cheeke, P. R., Pedersen, M. W. \& England, D. C. (1978). Canadian Journal of Animal Science 58, 783-789.

Cheeke, P. R., Powley, J. S., Nakaue, H. S. \& Arscott, G. H. (1983). Canadian Journal of Animal Science 63, $707-710$.

Gaunt, I. F., Grasso, P. \& Gangolli, S. D. (1974). Food and Cosmetic Toxicology 12, 641-650.

Johnson, I. T., Gee, J. M., Price, K. R., Curl, C. \& Fenwick, G. R. (1986). Journal of Nutrition 116, $2270-2277$.

Luchanskaya, V. N., Kondratenko, E. S., Gotovitz, T. T. \& Abubakirov, N. K. (1971). Khim Prir Soedin 7 , $431-435$.

Malinow, M. R., Connor, W. E., McLaughlin, P., Stafford, C., Lin, D. S., Livingston, A. L., Kohler, G. O. \& McNulty, W. P. (1981). Journal of Clinical Investigation 67, 156-162.

Malinow, M. R., McLaughlin, P. \& Stafford, C. (1980). Experimentia 36, 562-563.

Monsen, E. R., Hallberg, L., Layrisse, M., Hegsted, D. M., Cook, J. D., Mertz, W. \& Finch, C. A. (1978). American Journal of Clinical Nutrition 31, 134-141.

Oakenfull, D. G. (1981). Food Technology in Australia 33, 432-435.

Petersen, D. W. (1950). Journal of Nutrition 42, 597-607.

Pond, W. G. \& Yen J. T. (1984). Nutrition Reports International 29, 1191-1201.

Price, K. R., Curl, C. \& Fenwick, G. R. (1987b). Food Chemistry (In the Press).

Price, K. R., Johnson, I. T. \& Fenwick, G. R. (1987a). CRC Critical Reviews in Food Science and Nutrition (In the Press.)

Reshef, G., Gestetner, B., Birk, Y. \& Bondi, A. (1976). Journal of the Science of Food and Agriculture 27, 63-72.

Seeman, P. (1974). Federation Proceedings 33, 2116-2124.

Southon, S., Fairweather-Tait, S. J. \& Hazell, T. (1988). Proceedings of the Nutrition Society 47, (In the Press).

Southon, S., Livesey, G., Gee, J. M. \& Johnson, I. T. (1985). British Journal of Nutrition 53, 87-95.

West, L. G., Greger, J. L., White, A. \& Nonnamaker, B. J. (1978). Journal of Food Science 43, $1342-1343$. 